\section{ABORTO SEPTICO.}

\section{MANIOBRAS ABORTIVAS}

\author{
Dr. Luis Santamaría Páez* \\ Dr. Guillermo Castro Márquez** \\ Dr. Armando Lozano Carrillo***
}

La sepsis como problema de los Servicios Obstétricos adquiere entre nosotros un papel preponderante de modo de convertirse en la primera causa de mortalidad materna, a diferencia de otros medios en donde la razón de muerte está dada en primera instancia por la hemorragia.

Así, en el Instituto Materno-Infantil de Bogotá, en cuyo servicio de sépticas hemos realizado el presente trabajo, se presentaron 77 casos de muerte materna en el año 1966, de los cuales 44 por infección, 14 por toxemia, 9 por hemorragia. De las muertes por procesos sépticos 25 lo fueron en el curso de abortos, ordinariamente criminales, de ahí que nuestro enfoque se haga sobre este aspecto en particular, recalcando sus implicaciones clínicas y sociales. La Infectología, en el estado actual de nuestros conocimientos, se halla orientada por las investigaciones sobre los animales libres de gérmenes, la infección atenuada, la genética microbiana y los antimicrobianos.

Gnotobiótica. Una comprensión mejor del problema infeccioso ha sido suministrada con base en el concepto de los animales libres de gérme- nes (12) es decir, de formas de vida pura sin la presencia de la llamada flora microbiana asociada normal. En tales animales se podrá estudiar la infección en su carácter puro sin la interferencia de mecanismos de adaptación, sean morfológicos, nutricionales U orgánicos, determinados por la asociación bacteriana pre-existente.

En la tercera década del presente siglo Reyniers, Trexler y Ervin, en la U. de Notre-Dame en los Estados Unidos, y Glimstedt y más tarde Gustafsson en la U. de Lund en Suecia, inician la etapa moderna en la obtención y crianza de animales exentos de gérmenes, para 20 años más tarde lograr las primeras crías a partir de esos progenitores. Estos estudios representan la culminación de los iniciados en el siglo pasado con el ánimo de cultivar semillas en suelos esterilizados, y que Pasteur pidió ampliar a las formas de vida animal,

* Profesor Asistente. Departamento de Obstetricia y Ginecología de la Universidad Nacional. ** Instructor Asociado. Departamento de Obstetricia y Ginecología de la Universidad Nacional.

*** Residente 4. Departamento de Obstetricia y Ginecología de la Universidad Nacional. 
anticipando que la vida en tales condiciones sería imposible; poco después, Nencki, en Berna, exponía la teoría opuesta afirmando que la flora asociada es antagonista de la vida.

En estos seres se ha demostrado, entre otras, la etiología infecciosa de las caries dentales, la protección contra la Shiguelosis por el B. Coli, la necesidad de éste para desarrollar la amibiasis y para aumentar la resistencia a las irradiaciones; además, se avanza en el conocimiento de los procesos de envejecimiento y muerte del organismo. Se acepta hoy, que existe una acción estimulante de la flora sobre una serie de elementos celulares y humorales, a la vez que un efecto nocivo por las sustancias degradadas de modo que "Pasteur con su idea de la sinergia flora-huésped, y Nencki con la del antagonismo, tienen ambos razón" en el decir del profesor H. Gordon.

La Infección atenuada (20). El Dr. Simon con el ambicioso deseo de exponer una teoría sobre los gérmenes desde una perspectiva contemporánea analiza los varios factores que llevan a la enfermedad infecciosa, desde el contagio, las formas atenuadas, las formas latentes, etc.; los diversos aspectos de resistencia a la infección a nivel de cada individuo, aún más, de cada órgano; la variación que determinan los estados emocionales $y$ psíquicos. Analiza asímismo los factores culturales: el aislamiento de poblaciones, el hacinamiento, el aire contaminado, el más fácil contacto entre gentes de diversas latitudes, la aparición de nuevas drogas, la higiene y la salubridad públicas, etc., como factores capaces de modificar el curso de la infección.

Si la selección natural actúa en el sentido de propender por la supervi- vencia de los más fuertes, la selección cultural en sentido contrario busca la sobrevida de los menos dotados, para exponerlos en veces, a riesgos imprevistos. Quizás, en el curso de los años, a menos que aparezcan nuevos agentes patógenos, la convivencia pacífica de parásito-huésped sea la última forma de relación entre el hombre y los microbios.

Genética microbiana (13). La herencia bacteriana suele aceptarse como de tipo estable en cuanto que la multiplicación se hace por división de una célula madre en seres idénticos a ella.

La posibilidad de mutar por variación de un gen determinado, carácter transmisible a los descendientes hasta conformar una nueva especie, se ha calculado en una por cada cien millones de divisiones ocelulares, o sea que en un mililitro de cultivo en caldo habrá diez probabilidades para cada gen en una hora, mínima cantidad que puede acrecentarse por fenómenos de selección hasta alcanzar la predominancia dando una variación genética. Otra posibilidad está dada por las variaciones no genéticas inducidas por el medio ambiente.

La transmisión del material genético en las bacterias a semejanza de lo que ocurre en la reproducción sexual se conoce desde 1946; aportes posteriores han demostrado la existencia de cromosomas en la bacteria y, aún más, la transferencia de material genético de unas bacterias donadoras hacia otras receptoras mediante verdaderos puentes de cromatina o, también, el transporte de partículas sobre fagos en la llamada transducción. Se ha verificado además la capacidad de transformación en el ácido desoxiribonucleico de algunos gérmenes de modo de cambiar- 
se en otros, creando un nuevo genotipo.

Antimicrobianos. En los últimos años la investigación quimioterápica se halla centrada en las sustancias de origen microbiano que llamamos antibióticos, en cuyo campo se espera alcanzar la droga que ofrezca una máxima eficiencia, mínima o nula toxicidad, ausencia de resistencias, conforme a los postulados conocidos desde Paul Erlich.

Un arsenal terapéutico cada día enriquecido ha facilitado la lucha contra la infección, pero aún restan problemas sin solución. La experiencia clínica muestra como la introducción de un nuevo antibiótico va seguida a mayor o menor plazo de la aparición de cepas microbianas resistentes (3), de modo que las super-infecciones, la infección hospitalaria, continúan recargando los servicios hospitalarios. De ahí que la asepsia estricta, el prudente manejo de los antibióticos, la localización de las fuentes de infección, el romper su vía de propagación, la organización del hospital y sus infra-estructuras, conserven plena vigencia.

\section{MATERIAL Y METODOS}

Nos referimos a 665 pacientes tratadas en el Servicio de Sépticas del Instituto Materno-Infantil de Bogotá en un período de 15 meses a partir del 1\% de Marzo de 1966. Corresponden a un $8.7 \%$ de las ingresadas por aborto en el mismo lapso.

No se hizo selección alguna distinta del hallarse infectadas y presentar evidencia histológica de embarazo; se incluyen los casos de sepsis consecutiva a maniobras de intención abortiva en pacientes no embarazadas de las cuales reunimos 43 .

\section{Métodos}

El examen clínico se sigue de la clasificación del caso dentro de uno de los cuatro estados que se anotan en el Cuadro № 1.

\section{CUADRO N: 1}

\section{CLASIFICACION DEL ABORTO SEPTICO}

Estado 1: Infección localizada en la cavidad uterina.

Estado 11: Infección extendida a los anexos o estructuras parauterinas.

Estado III: Pelviperitonitis o peritonitis.

Estado IV: Septicemias, Shock bacteriémico, Insuficiencia renal, etc.

Los exámenes mínimos de rutina, los especiales que cada caso en particular requiera y las muestras para bacteriología se toman de inmediato.

En las infecciones localizadas a la cavidad uterina buscamos el enfriamiento del proceso, mediante penicilina-cristalina o Rifamicina S. V. para realizar entonces el raspado uterino.
En las infecciones extendidas a los anexos, estado II, hacemos un tratamiento mixto con antiflogísticos y Penicilina-estreptomicina o Cloranfenicol, o bien Rifamicina en iguales asociaciones hasta lograr la recuperación para efectuar el raspado uterino. Si persiste la patología anexial después de una terapia médica de 12 semanas realizamos la evacuación quirúrgica por laparotomía. 
Al estado III, peritonitis, pelviperitonitis, lo consideramos como una indicación quirúrgica inmediata a fin de drenar las colecciones purulentas. La hidratación adecuada, el balance electrolítico, la succión gástrica, los antibióticos son medidas de la rutina preoperatoria.

En casos de septicemia, estado IV, abocamos ante todo el problema de tratar o evitar el shock bacterémico. Aquí el balance hidroelectrolítico, los antibióticos, los corticoides, la heparina, las promazinas se usan en rela- ción a cada caso particular por la alta frecuencia de lesiones hepáticas o renales coexistentes. En el manejo quirúrgico de los casos que los requieran nos inclinamos cada vez más por la histerectomía, al igual que autores extranjeros (5-6-11).

\section{Resultados}

La discriminación de los casos por edades se muestra en el Cuadro N. 2 en donde se aprecia que la mayor incidencia corresponde al grupo de los 21-35 años, como es habitual en los servicios obstétricos.

\section{CUADRO N: 2}

EDAD DE LAS PACIENTES

\begin{tabular}{ccccccc}
\hline-15 & $16-20$ & $21-25$ & $26-30$ & $31-35$ & $36-40$ & $41-$ \\
3 & 91 & 191 & 192 & 101 & 68 & 13 \\
& & & $72,8 \%$ & & $12,2 \%$ \\
\hline
\end{tabular}

CUADRO N: 3

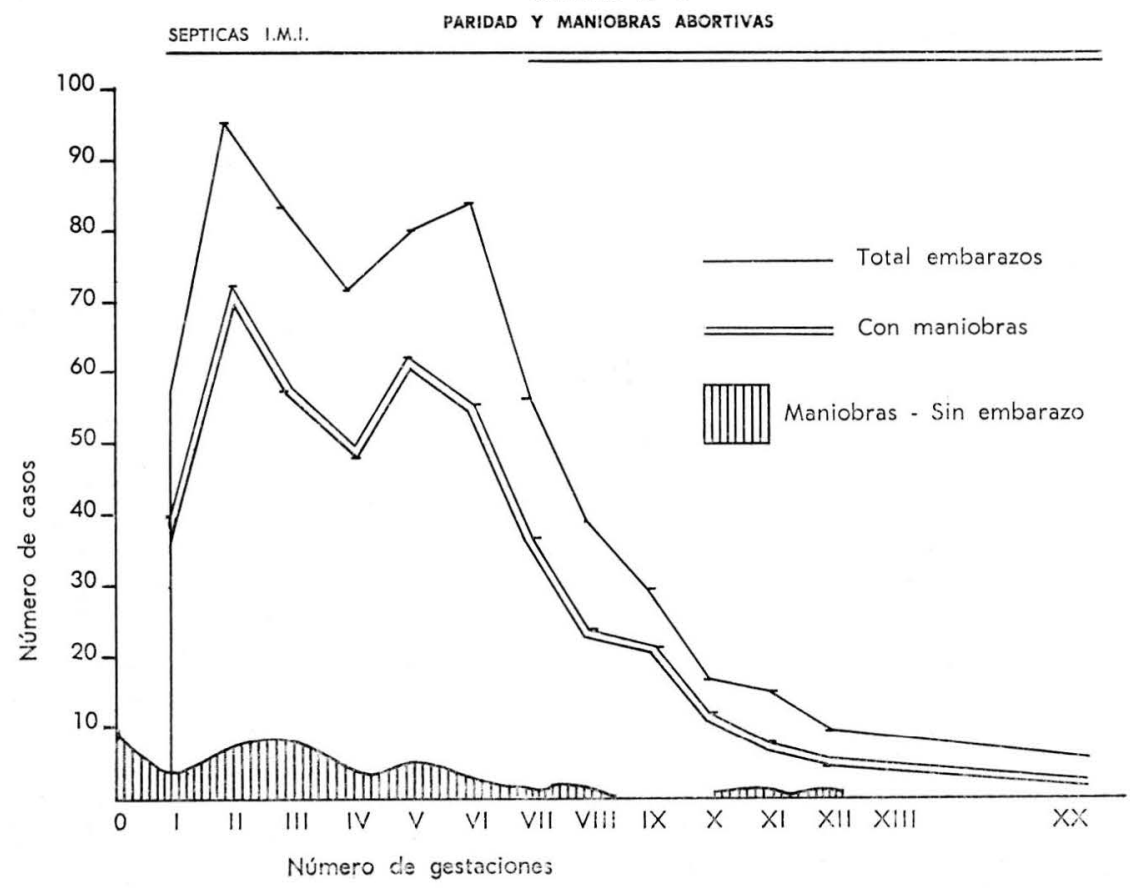


Llamamos la atención sobre tres pacientes menores de 15 años, dos de ellas apenas entradas en los 14.

La paridad -Cuadro № 3- se expresa en forma de gráfica que muestra como el gran volumen de los casos aparecen entre el $1^{\circ}$ y el $7^{\circ} \mathrm{em}$ barazo.

Se incluye allí mismo la representación del número de maniobras cuya línea sigue muy de cerca a la anteriormente trazada.

En la parte más baja de la gráfica se han marcado las maniobras reali- zadas en 43 mujeres no embarazadas, 8 de ellas nuligestantes.

En el Cuadro No 4 se demuestra la edad de gestación escogida para la realización del aborto. En buen número de casos se recurre a las abortadoras dentro de la primera semana de retardo menstrual; de ahí hasta la octava semana se suceden la mayoría de las interrupciones, cuya incidencia vuelve a aumentar un tanto en la décimo-segunda, y a partir de entonces sólo dan casos esporádicos hasta uno anotado para la semana 25.

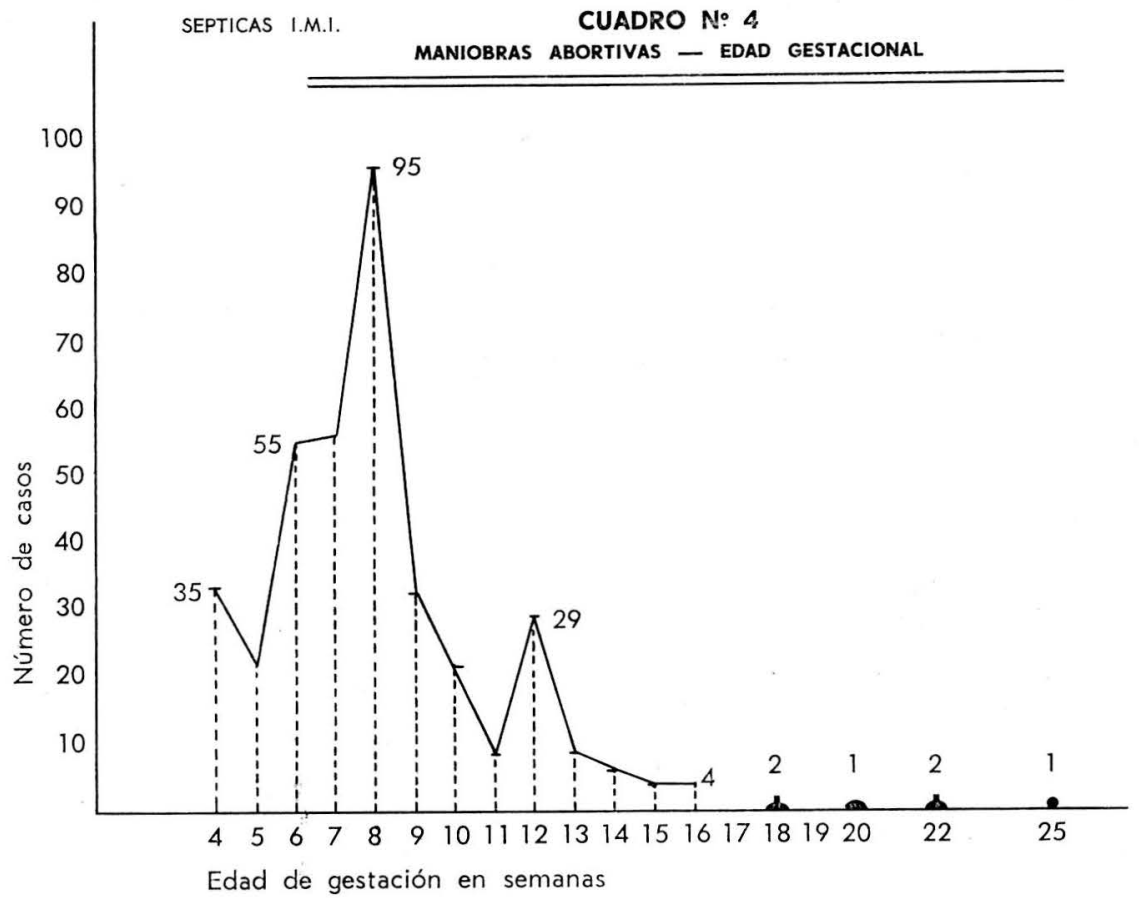

En $62 \%$ de los casos clasificados como patología anexial estaban presentes las maniobras abortivas.

La sepsis de curso severo, estados III y IV, se halló relacionada con tales maniobras en proporción directa, pues 73 casos de peritonitis sobre un

total de 88 presentaban esta condición; en 14 de estas pacientes no embarazadas, hubo maniobras de intención abortiva.

En 26 de 43 casos de septicemias y shock bacteriano se halló igualmente la presencia de maniobras 
CUADRO № 5

DISTRIBUCION DE PACIENTES SEGUN ESTADO DE SEPSIS Y MANIOBRAS ABORTIVAS

\begin{tabular}{|c|c|c|c|c|c|c|}
\hline & \multicolumn{4}{|c|}{ Maniobras } & \multirow[b]{2}{*}{ Niega maniobras } & \multirow[b]{2}{*}{ Total } \\
\hline & Con & embarazo & Sin & embarazo & & \\
\hline 1 & & 272 & & 17 & 150 & 439 \\
\hline il & & 51 & & 8 & 36 & 95 \\
\hline III & & 59 & & 14 & 15 & 88 \\
\hline IV & & 22 & & 4 & 17 & 43 \\
\hline TOTAL & & 404 & & 43 & 218 & 665 \\
\hline
\end{tabular}

abortivas que en 4 casos fueron practicadas a mujeres no embarazadas.

En pacientes no embarazadas con maniobras se halla una incidencia mayor de estados severos de sepsis lo que ofrece diferencia con lo anotado antes en nuestro Servicio; en $63 \%$ de los casos estudiados se haIló sepsis de grado II, III, y IV, con una alta frecuencia en particular pa- ra la peritonitis que en este grupo alcanza un $32.5 \%$, cuando su incidencia global es de $13,2 \%$. Esta estadística sin embargo, puede estar viciada de error en cuanto que a nosotros sólo confiesan las maniobras un $67,2 \%$ de las pacientes ingresadas en tanto que para otras encuestas en el mismo medio, la proporción llega al 83\% (22).

\section{CUADRO N 6}

BACTERIOLOGIA

\begin{tabular}{|c|c|c|c|c|c|c|}
\hline & I & II & III & IV & Total & $\%$ \\
\hline $\begin{array}{l}\text { B. Coli } \\
\text { Estafilococo }\end{array}$ & 172 & 46 & 63 & 29 & 310 & 57,8 \\
\hline Alb. & 69 & 18 & 23 & 8 & 118 & 22,0 \\
\hline Aur. & 4 & 3 & 4 & 2 & 13 & 2,4 \\
\hline \multicolumn{7}{|l|}{ Estreptococo } \\
\hline B. & 5 & 5 & 5 & 2 & 17 & 3,2 \\
\hline V. & 6 & 4 & 5 & 5 & 20 & 3,7 \\
\hline Escherichia & 10 & 1 & 5 & 1 & 17 & 3,2 \\
\hline Proteus & 17 & 2 & 8 & 1 & 28 & 5,2 \\
\hline Diplococo g. & 2 & 3 & 1 & 2 & 8 & 1,4 \\
\hline C. Welchii & - & - & - & 4 & 4 & 0,7 \\
\hline Pseudomona a. & - & 1 & 1 & 1 & 3 & 0,5 \\
\hline Cándida & 8 & 7 & 3 & 2 & & \\
\hline
\end{tabular}

Se estudian muestras de contenido uterino, pus abdominal obtenido durante la laparotomía o mediante colpocentesis, y esputo en las pacientes afectadas de neumonitis.

Así mismo se procesaron muestras a partir del bazo, de sangre auricu- lar y de abscesos pulmonares y peritoneales en el $30 \%$ de los casos de autopsia.

Se evidenció una buena correlación entre las distintas muestras tomadas a la misma paciente. 
Para el informe sólo se tomaron gérmenes patógenos; se informa la frecuencia de Candida a. cuya diseminación, que no ha ocurrido en ninguno de los casos estudiados por nosotros, ofrece alguna incidencia para otros medios (10).

Los gérmenes hallados en orden de frecuencia son el colibacilo, estafilo$\mathrm{coco}$, estreptococo, proteus, escherichia, neisseria, welchii y pseudomona. El colibacilo cubre el $58 \%$ de los casos, solo o en asociaciones con estafilococo y estreptococo.

En los distintos grados de la sepsis la correlación bacteriológica, aún en los casos más severos, III y IV que determinaron mortalidad, mostró la misma distribución de gérmenes. Sin embargo, como el número de ellos es bastante diferente vale anotar que el estafilococo aureus pasa a tener predominancia sobre el albus ya que se lo halló en 7 de once pacientes muertas por peritonitis, y en una a causa de septicemia. El estreptococo, así mismo, relieva su patogenicidad pues aparece en trece pacientes de un total de treinta que fallecieron.

El C. Welchii se anotó en tres casos de mortalidad, con cuadro clínico de shock bacterémico; en otra oportunidad en que se lo aisló parece tratarse de una forma no patógena.

Los datos generales y los parciales de los distintos gérmenes concuerdan con lo informado para casos clínicos similares en nuestro medio y fuera de él (14-16-19).

\section{CUADRO N: 7}

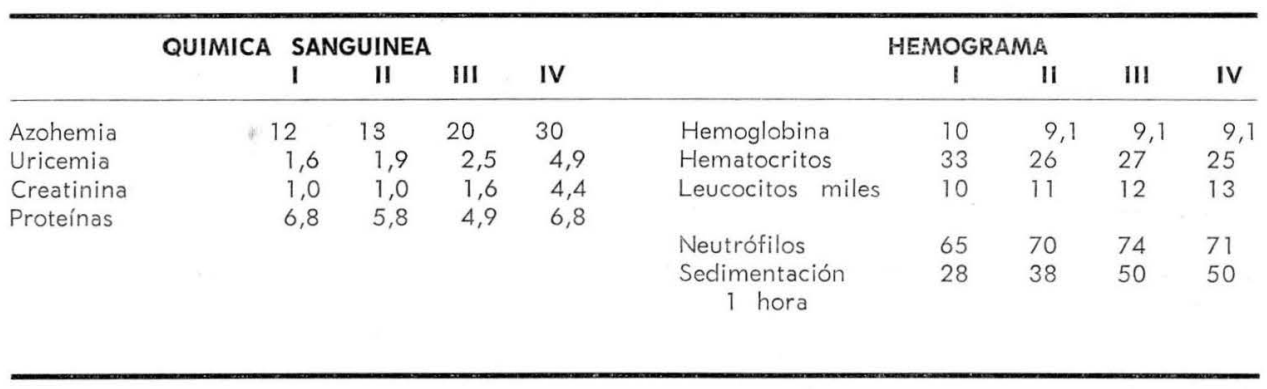

En Estados I y II la Química sanguínea oscila dentro de límites normales. Una anemia aparente, con recuento leucocitario algo aumentado es el hallazgo habitual; la sedimentación globular está aumentada, especialmente en los estados II en donde pueden verse ascensos hasta los 100 milímetros. Para el estado III la Química sanguínea aparece francamente modificada en el $13 \%$ de los casos, con aumentos en la azohemia, la creatinina y la uricemia; hay tenden- cia a la acidosis sin llegar a datos extremos; igualmente el sodio, el cloro y el potasio oscilan dentro de parámetros normales. La leucocitosis más aparente que en los estados anteriores alcanza en promedio los 14.000 leucocitos, con neutrofilia. La sedimentación globular alcanza un nivel promedio de 50 milímetros.

Para el estado IV la azohemia se halla en valores de $30 \mathrm{mg}$., con uricemia de 5 y creatinina de 4,3. En 
el $37,3 \%$ de los casos se aprecian datos francamente anormales para las 3 sustancias anotadas. En la mitad de los casos la bilirrubina llega hasta 9,6 en la total, con predominio de la fracción directa.

La leucocitosis ordinariamente acentuada ofrece sin embargo grandes oscilaciones con datos extremos de 7.500 y 35.200 . La neutrofilia es el hallazgo habitual, pero la linfocitosis en veces hasta del $60 \%$, con neutropenia, es signo de mal pronóstico.

\section{Manejo clínico}

Se orienta fundamentalmente al diagnóstico precoz de las complicaciones.

La astenia, vagas molestias abdominales y discretísima sensibilidad con resistencia de la pared, acostumbran a preceder los claros signos peritoneales en el inmediato post-operatorio del raspado uterino. Fiebre sostenida, inquietud psicomotora, vómito, dolor bien localizado, marcan cl desarrollo agudo de los abscesos pélvicos del estado II, cuya palpación muestra el crecimiento de las masas anexiales y aconseja la laparotomía inmediata.

Un repunte febril tras unos días de recuperación post-operatoria, suele ser la manifestación aparente de un absceso, ordinariamente de pared; cuando hemos mantenido por largo tiempo la terapia intramuscular, habrá que buscarlo en los glúteos.

La neumonitis de curso dramático, con punta de costado y gran signología pulmonar ha sido la excepción. El aleteo nasal, casi siempre discreto; algo de dificultad respiratoria y un poco de acrocianosis, suelen ser los heraldos de una lesión solapada del pulmón, ya evidenciable por el radiólogo, mucho más extensa de lo que imaginábamos. El mal estado general, la oliguria y coluria, las alteraciones del sensorio, la hipotensión arterial, el enfriamiento con palidez de piel y mucosa, y la aparición de dermopatías del tipo del livedo reticularis, marcan el estado IV con la temible insuficiencia renal aguda.

La ictericia, inicialmente moderada, que apenas tiñe las escleras, anuncia el compromiso hepático, de curso siempre grave.

\section{CUADRO № 8}

MANEJO TERAPEUTICO

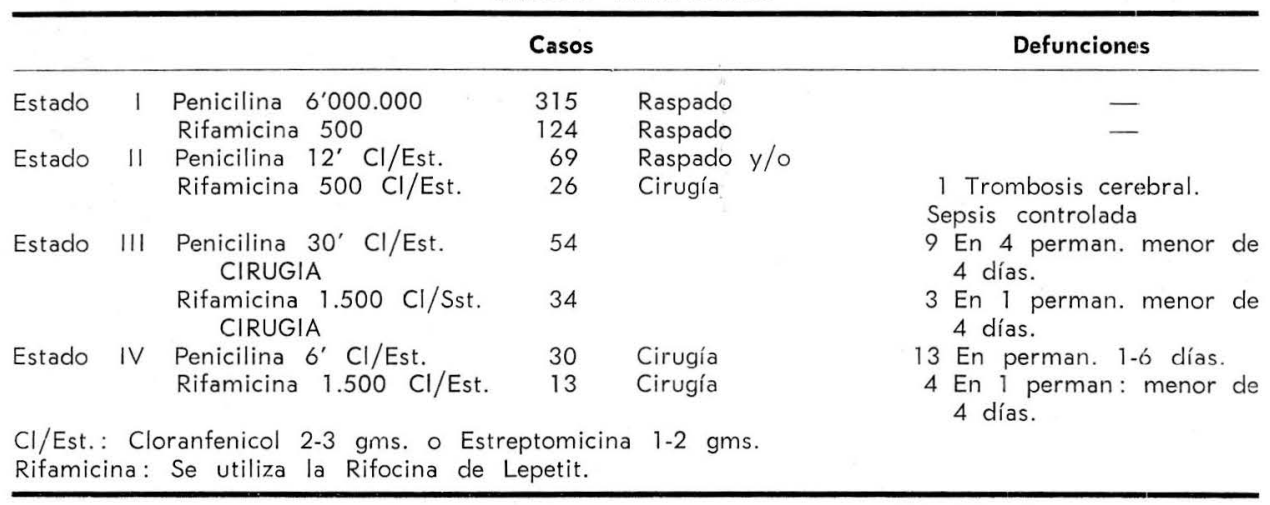


Se presenta un esquema de tratamiento en donde marcamos principalmente 2 tipos de antibioterapia, en un caso la penicilina sola 0 en asociaciones con el Cloranfenicol o la Estreptomicina, en el segundo tipo la Rifamicina en iguales condiciones.

Se marca la realización de la cirugía después del número de casos para significar que anteponemos el tratamiento médico hasta lograr el enfriamiento del proceso, en cambio en los estados III aparece antes para insistir en la precocidad de su realización.

Para el estado II la intervención está condicionada a la apreciación en el control clínico que en los casos ordinarios se realiza después de una semana de tratamiento médico. Se exceptúan aquellos de crecimiento exagerado de las masas anexiales o cuando evolucionan a pesar de la medicación en los cuales preferimos la intervención inmediata al diagnóstico de la complicación. Para los estados I y II los resultados son ampliamente satisfactorios con cualquiera de los 2 planes de manejo, en los que no se anotó diferencia significativa en cuanto a tiempo de hospitalización, número de cirugías, o complicaciones. En presencia del compromiso peritoneal manejamos los casos como cirugías de urgencia cuya preparación se inicia por la hidratación, para corregir desequilibrios hidroelectrolíticos o metabólicos, en particular la tendencia a la acidosis; la succión gástrica se instala a permanencia; el cateterismo venoso se hace de inmediato y se prescribe una antibioterapia enérgica.

Los hallazgos operatorios son ciertamente dramáticos; pus libre o coleccionada en volumen variable de 500 a 2.000 cm.; abscesos sub-fréni- $\cos$ en $33 \%$ de las pacientes; perforación uterina fácilmente apreciable en 10 casos; en 14 pacientes se extrajeron sondas de melatón de la cavidad peritoneal. En 2 oportunidades se apreció verdadera gangrena peritoneal con zonas de necrosis $y$ gas libre en abdomen. La cuarta parte de las pacientes requirió la histerectomía total.

\section{CUADRO N: 9 \\ INTERVENCIONES QUIRURGICAS REALIZADAS}

\begin{tabular}{lr}
\hline Raspados & 628 \\
Laparotomías & 78 \\
Histerectomías & 27 \\
Salpingo-oforectomías: & \\
$\quad$ Derecha & 26 \\
Izquierda & 13 \\
Colpotomías & 12 \\
Toracentesis & 1 \\
\hline
\end{tabular}

Un buen drenaje de las diversas colecciones purulentas es indispensable y se dejan drenes en las fosas ilíacas y los espacios sub-frénicos. El uso de Rifamicina local (9-10-4) a semejanza de lo informado por algunos autores, se programó luego de la laparotomía dejando $500 \mathrm{mg}$. en grupos de pacientes, de modo de poder establecer una comparación; sin embargo, el entusiasmo de los cirujanos hizo dejarla en prácticamente todos los casos, de modo que hemos hecho la estimación sobre informes de años anteriores (16-19); esta medida junto con la experiencia adquirida para los drenajes, disminuyó notablemente las recidivas locales y las complicaciones de pared.

Los resultados finales se resienten de la severidad de los casos y por esto no los consideramos tan malos, aunque esperamos mejorarlos.

La mayor dificultad terapéutica se encuentra en los estados IV, cuyo 
manejo no puede someterse a esquemas rígidos. Ante todo debe recordarse la alta incidencia de patología renal y hepática, a veces asociadas, para la elección correcta de las drogas y su dosis, para el volumen de líquidos y para la administración de los electrolitos. La acidosis, presente o insinuada debe tratarse de inmediato. Nuestro objetivo es evitar el shock bacteriémico o tratarlo si ya está presente.
Ante lesiones hepáticas se obtuvieron los mejores resultados con la $\mathrm{Ri}$ famicina cuya concentración elevada a nivel biliar, mostró clínicamente actividad terapéutica. Esta droga pigmenta de amarillo rojizo la piel y conjuntivas cuando se la usa en dosis altas sostenidas; es un efecto de depósito local del medicamento y no requiere suspender el tratamiento.

\section{CUADRO № 10}

\section{COMPLICACIONES POST-OPERATORIAS}

\begin{tabular}{|c|c|c|c|c|}
\hline \multirow[t]{6}{*}{ Abscesos: } & & & Exacerbación por raspado & 29 \\
\hline & Subfrénico & 1 & Fístula de intestino delgado & 2 \\
\hline & Pared ab. & 14 & Herida del ciego & 1 \\
\hline & Cúpula vag. & 2 & Apertura de la vejiga & 1 \\
\hline & Glúteo & 3 & Tromboflebitis & 2 \\
\hline & Mamario & 1 & Ulcus aguda & 2 \\
\hline Neumonitis & & 16 & Oclusión & 1 \\
\hline Hepatitis & & 6 & Reacciones psicóticas & 5 \\
\hline Pielonefritis & & 5 & & \\
\hline Insuficiencia & cardíaca & 3 & & \\
\hline Evisceración & & 1 & & \\
\hline
\end{tabular}

Las complicaciones más frecuentes son las relacionadas con la infección. Su incidencia ha descendido en nuestro Servicio si se la compara con la observada en años anteriores (19). Sólo un absceso subfrénico contabilizamos ahora, esto debido en nuestro sentir a un mejor drenaje por la experiencia adquirida. Los abscesos de pared abdominal, los de cúpula vaginal y los glúteos son de fácil aparición en este tipo de pacientes. Se anotó un caso de evisceración. Por su rara ocurrencia llama la atención un absceso mamario aparecido en el curso de una septicemia; casos semejantes han sido informados por algunos autores (6).

La alta incidencia de neumonitis confirma lo anotado por Pullen (17) en torno a la cirugía abdominal al- ta, practicada con anestesia general, en pacientes de bajas defensas que permanecen largo tiempo en reposo. En los estudios bacteriológicos de esputo se hallaron el colibacilo, el estafilococo y el estreptococo.

La incidencia de hepatitis, seis casos, se refiere en particular a estados IV, en los cuales es posible que algún tipo de lesión hepática viniese evolucionando desde su ingreso, pero que sólo se hace aparente en el postoperatorio.

Las exacerbaciones post-raspados ofrecen aún una alta incidencia y se refieren fundamentalmente a casos intervenidos cuando la sepsis no había sido suficientemente controlada; su diagnóstico y tratamiento oportunos evitan la diseminación y en esta 
serie de casos no hubo ningún deceso por esta causa.

Las pielonefritis son consecutivas a los cateterismos vesicales.

La insuficiencia cardíaca ha sido relacionada con las toxinas bacterianas (18) y de hecho ha ocurrido sin antecedentes de patología cardíaca.

Dos hematemesis severas por úlceras agudas recibieron tratamiento médico.

Caso curioso el de un estado III en el cual se extrajo una sonda de la cavidad abdominal, que presentaba mínima reacción peritoneal y evolucionó con un postoperatorio fácil hasta el día décimo cuando presentó una oclusión aguda, que cedió a la succión gástrica continua.

En venas cateterizadas por largo tiempo aparecieron dos tromboflebitis.

Como accidentes quirúrgicos se anotan dos heridas del intestino delgado, una del ciego, y una apertura de la vejiga.

\section{Reingresos}

Cuatro pacientes de estado III requirieron nueva hospitalización para tratamiento de secuelas sépticas. Esto confirma lo difícil que es el criterio de curación en la peritonitis postaborto.

Siete pacientes de estado II volvieron al Servicio. Una murió a consecuencia de un accidente cerebro-vascular por trombosis. Seis abscesos residuales recibieron tratamiento: tres cedieron a la medicación antibiótico-antiflogística, y en tres se requirió la cirugía.

Nuestras pacientes se dan de alta después de un chequeo clínico completo que incluye un buen examen pélvico. Es posible que estas anexitis sean casos reagudizados al retornar la paciente a su vida marital y a su medio ambiente de miseria.

Un estado I reingresó por un absceso tubo-ovárico derecho. En dos casos más la hospitalización se renovó por hemorragia genital debida a raspado incompleto.

\section{Signos de mal pronóstico}

Se refieren fundamentalmente a las alteraciones renales, hepáticas y pulmonares.

Con signos clínicos de insuficiencia renal y niveles de azohemia más allá de $30 \mathrm{~mm}$. por 100 c.c. de sangre se encontraron 27 pacientes, 11 de ellas afectadas de peritonitis y 16 de septicemia. En el estado III, la azohemia alcanzó $44 \mathrm{~mm}$. en promedio, junto con uricemias de $4,4, y$ creatinina de 3,5 ; el germen aislado fue el colibacilo solo o asociado al estafilococo aureus, y en un caso el proteus morgagni. Para este grupo la mortalidad fué del $54 \%$.

En 16 estados IV con insuficiencia renal se halló la azohemia en $49 \mathrm{~mm}$. la uricemia en 6,3 y la creatinina en 8,1 como valores promedios. Los gérmenes causantes en orden de frecuencia son: colibacilo, estreptococo, welchii, y proteus; en los casos más severos estaba presente el estreptococo viridans en asociación con el c. welchii. La mortalidad para este grupo alcanzó el $75 \%$.

La ictericia estuvo presente en 34 pacientes, 13 de estado III, y 21 del estado IV.

Para los casos de peritonitis se halló un promedio de $16 \mathrm{mgm}$. de bilirrubinemia total, especialmente aumentada a expensas de la fracción directa que alcanzó $11 \mathrm{mg}$. El coli- 
bacilo como único germen patógeno cubrió la mayoría de los casos, en segundo lugar estuvo asociado al estafilococo aureus, $y$ en un caso con el estreptococo viridans; el proteus, por sí solo, determinó un caso. La mortalidad para este grupo fué del $46 \%$.

En 21 casos de septicemia la bilirrubinemia total dió un promedio de $9,6 \mathrm{~mm}$., con un dato de 6,1 para la directa; un caso llegó hasta $22 \mathrm{~mm}$. en la dosificación total. El colibacilo como único germen causante se encontró en la mitad de los casos, en segundo lugar estuvo la asociación de un colibacilo y estafilococo aureus; el estreptococo y el c. welchii ocuparon el tercer lugar con tres casos. Para este grupo la mortalidad llegó al $52 \%$.

Cuando se asocian las lesiones renales y hepáticas el pronóstico se ensombrece, pues de 11 pacientes con esta condición, 10 murieron.

Cuatro mujeres presentaban neumonitis desde su ingreso, y en 16 más ésta apareció en el post-operatorio; de ellas 9 murieron.

\section{CUADRO NN 11}

\section{MORTALIDAD HOSPITALARIA}

\begin{tabular}{cc}
\hline $\begin{array}{c}\text { Mortalidad hospitalaria en I .M. I. } \\
0,27 \%\end{array}$ & Mortalidad en Sépticas I. M. I. \\
Mortalidad materna: & $\mathbf{4 , 5 \%}$ \\
$\begin{array}{c}\text { Número de muertas } \\
\text { Nacidos vivos }\end{array}$ & $0,38 \%$ \\
\hline
\end{tabular}

CUADRO N 12

MORTALIDAD POR ESTADOS

\begin{tabular}{cccc}
\hline Estado & Defunciones & Casos & $\%$ \\
\hline I & - & 439 & 0 \\
II & 1 & 95 & 1,0 \\
III & 12 & 88 & 13,5 \\
IV & 17 & 43 & 39,5 \\
\hline
\end{tabular}

En nuestra relación de mortalidad incluímos todos los casos de pacientes fallecidas en el Servicio no importa cual haya sido su permanencia. El deseo es insistir sobre la gravedad de estos procesos.

Los hallazgos de autopsia confirman los datos clínicos. En 27 mujeres a quienes se les practicó autopsia las lesiones más frecuentes fueron las propias de la septicemia, con 12 casos; los exámenes bacteriológi- cos verificaron la presencia de los mismos gérmenes hallados en vida.

En el riñón se hallaron lesiones en 18 pacientes, 12 de ellas de gran severidad que se refieren a necrosis tubular corticales, nefrosis biliar y hemoglobinúrica. En un caso de necrosis tubular se hallaron signos de recuperación histológica y se admitió que esta paciente ya curada de la septicemia y en vía de mejoría renal, 
CUADRO N 13

27 AUTOPSIAS - HALLAZGOS PRINCIPALES

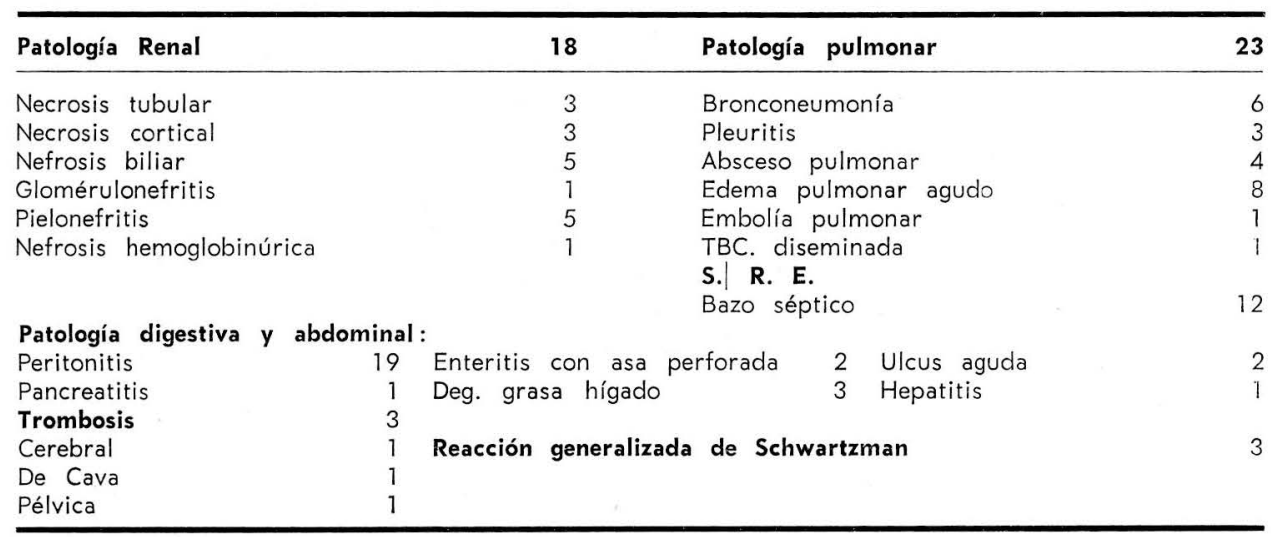

murió a consecuencia de una embolía pulmonar múltiple.

En 19 autopsias había evidencia de peritonitis en evolución. En sendos casos además, se halló pancreatitis aguda y hepatitis sépticas. En dos casos había asas perforadas y en una colitis pseudomembranosa. Se informaron así mismo dos úlceras agudas sangrantes y tres degeneraciones grasas del hígado.

La patología pulmonar es de alta incidencia, especialmente por bronconeumonías, varias de ellas con abscesos; en ocho casos el edema agudo del pulmón fué la causa final de la muerte.

Hubo tres casos de pleuritis con derrame y una embolía múltiple que causó el deceso de una mujer en vía de recuperación de sepsis y con nefropatía. Se anotó una TBC miliar diseminada a favor del proceso de septicemia inducida en una paciente no embarazada, en quien las maniobras abortivas fueron practicadas por amenorrea, debida a extensas lesiones de tuberculosis genital. Se ha anotado la rara concomitancia de lesiones pulmonares evolutivas y genitales en la misma paciente (1).

A nivel genital se hallaron dos panmetritis y siete endometritis agudas necrotizantes, frecuentemente asociadas al estreptococo. Su número parece bajo pero debe tenerse en cuenta que las pacientes ordinariamente habían sido sometidas a raspado y con frecuencia histerectomizadas.

Se informaron cuatro trombosis, dos de ellas mortales.

En tres pacientes se hizo diagnóstico de reacción generalizada de Schwartzman, una de ella llegó hasta la hipofibrinogenemia. En otro aparte de este trabajo el Profesor Velasco hace un comentario especial de estos casos, cuya relación con toxinas de gérmenes gram negativos en mujeres embarazadas se ha recalcado (5-14).

\section{COMENTARIOS - CONCLUSIONES}

Recientemente se ha publicado una investigación realizada en Minnesota (2), en donde ocurren el $2 \%$ de los 
partos de los Estados Unidos y por tanto puede aceptarse como un muestreo suficientemente amplio. Pues bien, allí en los 15 años posteriores a 1950, sólo hubo 21 mujeres muertas por aborto criminal, con una relación numérica de un caso por cada 61.988 nacidos vivos. Entre nosotros, en 15 meses ocurren 30 muertes por aborto séptico, seguramente inducido (22) con una relación de 1 por 794 nacidos vivos.

La clasificación utilizada, de fácil aplicación, ha facilitado el manejo de los casos, el establecimiento de conductas quirúrgicas, y da un margen razonable para el pronóstico. Nuestros resultados finales son relativamente buenos pues manejamos casos difíciles, de gran severidad. No siempre puede inculparse a la consulta tardía por parte de las pacientes ya que en la revisión hecha la duración de los síntomas y el tiempo transcurrido después de las maniobras es sensiblemente igual para los diversos estados. Quizás puedan más la agresividad de los gérmenes y el hambre crónica junto con las condiciones en que se realiza el aborto. El manejo clínico bien orientado busca mejorar el pronóstico mediante la pesquiza de las complicaciones.

Los antibióticos manejados, en dosis generosas, no han ofrecido respuestas nocivas en particular la $\mathrm{Pe}-$ nicilina y la Rifamicina de gran tolerancia y baja o nula toxicidad. En cuanto al Cloranfenicol no hemos observado las depresiones medulares que se anotan para él, pero las observaciones de Junis (15) que incluyen estudios seriados de medula ósea y sangre periférica en todos los pacientes que la reciben, le llevan a afirmar que siemore hay fenómenos tóxicos de depresión, algunos irreversibles. Con tal consideración esperamos ser más cautos en el manejo de ese medicamento $y$ en un futuro inmediato esperamos ensayar otro de menor toxicidad.

Como veremos ahora en la segunda parte de este trabajo dedicada a las maniobras abortivas el aspecto del aborto séptico no es puramente médico sino de grandes implicaciones socio-culturales.

\section{CUADRO NN 14}

\section{COSTO HOSPITALARIO}

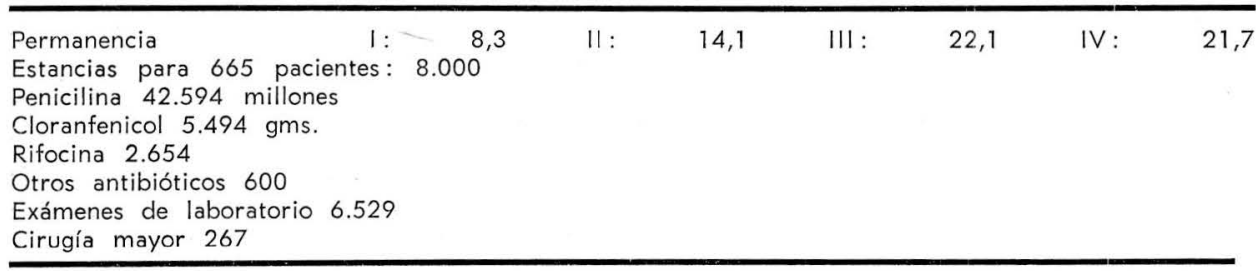

\section{Costo Hospitalario}

El servicio de sépticas, con 18 camas representa para el Instituto Materno Infantil un enorme consumo de diversos elementos cuya evaluación nos ha parecido debe hacerse en relación a las necesidades del mismo
Instituto, en donde la afluencia de pacientes en progresivo crecimiento ha llegado a reducir la permanencia hospitalaria a 3,3 en el año de 1966. Es así que con el volumen de estancias y de gastos del servicio de sépticas habrían podido atenderse algo 
así como 2.300 partos, o varios centenares de pacientes quirúrgicas.

\section{Hallazgos imprevistos}

Sobre 480 pacientes se informaron $7,5 \%$ de serologías positivas; este dato requiere una investigación, pues de ser válido habría que admitir un ingreso anual de 2.100 sifilíticas al Instituto. Además se halló que sólo un $5 \%$ de las pacientes son $\mathrm{RH}$ negativas lo que está en desacuerdo con lo habitualmente observado en la raza blanca, y es mucho más cercano de lo aceptado para las razas mongólicas.

\section{INVESTIGACION SOBRE MANIOBRAS ABORTIVAS $Y$ SUS RELACIONES SOCIO-CULTURALES}

Tuvimos oportunidad de entrevistar un buen número de mujeres confesas de aborto provocado quienes admitieron contestar un formulario previamente preparado.

Las dividimos por su estado civil y a éste hemos relacionado los diversos puntos investigados.

$\mathrm{Si}$ las distribuímos por edades (Cuadro № 15), tomando como referencia el porcentaje, dado el distin- to número de solteras y casadas, vemos cómo difiere para estos dos grupos la incidencia del aborto provocado. En las solteras se inicia con cifras altas en edad muy temprana, antes de los 20 años, para hacerse más frecuente hacia los 30 , de donde desciende abruptamente. En las casadas en cambio, se inician los datos elevados después de los 20 años y se mantiene hasta los 40 en alta frecuencia.

Al estudiar la relación de abortos provocados y paridad (Cuadro № 15) se entiende claramente la diferencia anotada en los grupos de edad. En tanto que las primigestantes solteras recurren al aborto con inusitada frecuencia, como para afirmar que en la primeriza el aborto es provocado hasta que no se demuestre lo contrario, es obvio que la mujer casada solo lo hará de manera excepcional; igualmente las solteras dan alto número de maniobras en la segunda $y$ tercera gestación, un $43,4 \%$ del total de abortos, cuando las casadas en este grupo sólo llegan al 13,9\%. A medida que aumenta el número de gestaciones y la edad de la mujer aumentan los casos de las mujeres casadas.

\section{CUADRO Nং 15}

EDAD DE LAS PACIENTES (en porcentaje)

\begin{tabular}{|c|c|c|c|c|c|c|c|c|c|}
\hline & & -15 & $16-20$ & $21-25$ & $26-30$ & $31-35$ & $36-40$ & 41 & Total \\
\hline $\begin{array}{l}\text { Solteras } \\
\text { Casadas }\end{array}$ & & 0,6 & $\begin{array}{r}19,9 \\
6,1\end{array}$ & $\begin{array}{l}34,7 \\
26,6\end{array}$ & $\begin{array}{l}24,2 \\
32,2\end{array}$ & $\begin{array}{l}12,4 \\
19,4\end{array}$ & $\begin{array}{r}5,5 \\
11,6\end{array}$ & $\begin{array}{l}1,8 \\
3,3\end{array}$ & $\begin{array}{l}99,1 \% \\
99,2 \%\end{array}$ \\
\hline \multicolumn{10}{|c|}{ PARIDAD (en porcentaje) } \\
\hline \multicolumn{3}{|c|}{ Primigestantes } & \multicolumn{5}{|c|}{ Solteras : $13 \%$} & \multicolumn{2}{|c|}{ Casadas: $2,2 \%$} \\
\hline $\begin{array}{l}2-3 \\
4-5-6 \\
7-8-9 \\
9 \text { y más }\end{array}$ & $\begin{array}{l}\text { Gestaciones } \\
\text { Gestaciones } \\
\text { Gestaciones } \\
\text { Gestaciones }\end{array}$ & & & & $\begin{array}{c}43,4 \\
27,8 \\
14,1 \\
1,2 \\
99,5 \%\end{array}$ & & & & $\begin{array}{l}13,9 \\
46,1 \\
22,7 \\
14,4 \\
99,3 \%\end{array}$ \\
\hline
\end{tabular}


CUADRO № 16

RELIGION - ACTITUD HACIA LA ABORTADORA

\begin{tabular}{lrcccc}
\hline & Católicas & Practicantes & No practicantes & No católicas & Sin dato \\
\hline Solteras & 160 & 148 & 7 & 1 & 2 \\
Casadas & 178 & 169 & 5 & & Satisfechas \\
& Rencorosas & Agradecidas & Arrepentidas & 1 & dato \\
Casadas & 110 & 43 & 20 & 1 & 6 \\
Solteras & 103 & 41 & 12 & 3 \\
\hline
\end{tabular}

En nuestra encuesta sobre estos aspectos hallamos nuevamente una mayor incidencia de mujeres casadas $(52,7 \%)$ como usadoras del aborto para planificar su familia, ya que al Instituto ingresan (Cuadro № 24), cuando menos, un $66 \%$ de mujeres solteras.

Estas pacientes en su gran mayoría, por no decir que todas, son católicas, casi siempre practicantes $(94 \%)$ y de hecho suelen confesar y comulgar durante su permanencia hospitalaria. Presentan así una disparidad de criterios difícil de entender a menos que se valore el fenómeno como un aspecto de su incultura general.

Sólo se muestran arrepentidas de su actuación 32, ordinariamente quienes se han realizado maniobras por sí mismas. El sentimiento más fre- cuente hacia la abortadora se expresa en dos posiciones: o están agradecidas, 48, o se muestran con rencor, 213, pero éste es más bien un reproche o resentimiento por lo que ellas consideran un servicio fallido que las ha abocado a una enfermedad. De ninguna manera se encuentra contenido ético en la actitud hacia la abortadora como tampoco aparece la moral en su apreciación del aborto realizado. $\mathrm{Si}$ no vuelven a provocarse abortos ciertamente será por temor a la enfermedad que han padecido o a la severidad de los casos que han tenido oportunidad de apreciar mientras están hospitalizadas, y no en modo alguno por consideraciones ético-religiosas.

Una casada y una soltera estaban satisfechas por la realización del aborto.

\section{CUADRO NN 17}

\begin{tabular}{lccccc}
\hline Quién hizo el aborto & Casadas & Solteras & Total & Casadas & $\begin{array}{c}\text { Cuánto cobró } \\
\text { Solteras }\end{array}$ \\
\hline Abortadoras & 107 & 78 & 185 & $\$ 58,00$ & $\$ 73,00$ \\
Enfermeras & 26 & 24 & 50 & 69,00 & 90,00 \\
Parteras & 7 & 4 & 11 & 61,00 & 77,00 \\
Droguistas & 6 & 3 & 9 & 70,00 & 50,00 \\
Médicos & 4 & 9 & 13 & 275,00 & 208,00 \\
Ella misma & 14 & 13 & 27 & - & - \\
Otros & 16 & 30 & 46 & 65,00 & 45,00 \\
\hline
\end{tabular}


El número de abortadoras profesionales al parecer va en aumento. Se trata de mujeres que no conocen ocupación distinta, quienes no ponen reparos para su actuación y unas cuantas veces buscan a las pacientes para ofrecerles sus servicios.

Hay otras, 11, que son además comadronas o parteras, y seguramente por esta razón tienen fácil acceso a las mujeres a quienes antes habían atendido en sus partos.

De especial gravedad nos parece el número de auxiliares de enfermería, empelados de droguerías y médicos inculpados, en cuanto que su manto de saber acerca de la salud y su disfraz de profesionales honrados facilita su ejercicio criminal. Algunas veces practicaron el aborto en mujeres que no lo deseaban, quienes habían consultado por distintas manifestaciones normales o patológicas de la gestación.

Las sumas que perciben por su actuación, (Cuadro № 17), relievan su condición de miseria moral y pecuniaria.

CUADRO № 18

\begin{tabular}{lcclrr}
\hline Método & Casadas & Solteras & Sitio de las Maniobras & Casadas & Solteras \\
& & & & & \\
& & & & \\
Sonda & 177 & 154 & Casa de la abortadora & 107 & 102 \\
Sonda-varilla & 83 & 79 & Casa de la paciente & 60 & 43 \\
Sonda varilla Speculum & 18 & 20 & Droguerías & 6 & 3 \\
Sonda-varilla & 4 & 5 & Consultorios & 4 & 5 \\
Speculum-guantes & 21 & 13 & Sin dato & 4 \\
Man. repetidas & & & & \\
\hline
\end{tabular}

Se confirma sin lugar a dudas la extensión del método de la sonda, 331 casos, ya sea co nvarilla o sola; usada sin espéculo y sin guantes se convierte en el método agresivo, ciego y séptico que llena nuestras camas hospitalarias de enfermas gravemente infectadas y traumatizadas.

El hogar de la paciente es con frecuencia (103 casos) el sitio elegido para la realización de las maniobras, lo cual muestra cómo las abortadoras trabajan a domicilio, extendiendo enormemente su campo de actividad a la vez que disminuyen la probabilidad de ser localizadas. Un gran número de casos, 209, se realiza en sitios destinados al efecto en casa de la abortadora de modo que unas cuantas veces nos es suficiente- mente identificada con nombre y dirección.

En Droguerías y consultorios se hizo el aborto en 17 oportunidades; una de éstas por la enfermera auxiliar de un médico en las horas en que éste no asistía.

\section{CUADRO NN 19} ACTITUD DEL MARIDO

\begin{tabular}{lccr}
\hline & Solteras & Casadas & Total \\
\hline Sabe del aborto & 74 & 84 & 158 \\
Instigador & 30 & 43 & 73 \\
Partícipe & 2 & 5 & 7 \\
Indiferente & 13 & 13 & 26 \\
\hline
\end{tabular}

En buen número de casos el aborto se realiza a escondidas del marido o éste pretende ignorar lo sucedido. 
Actúa como instigador en 73 ca- luego en la motivación para el aborsos, logrando con amenazas de aban- to la responsabilidad del marido se donar el hogar, por ejemplo, o por aumenta con los casos de abandono otros medios, que la mujer acceda a del hogar, mala relación familiar, mal realizarse el aborto. Como se verá trato a la esposa, etc.

\section{CUADRO № 20}

\section{MOTIVACION PARA EL ABORTO}

\begin{tabular}{|c|c|c|c|}
\hline & Casadas & Solteras & Total \\
\hline No consigue trabajo por los hijos & 2 & 17 & 19 \\
\hline Abandono del hogar por el marido & 10 & 7 & 17 \\
\hline Soltería & & 10 & 10 \\
\hline Temor a los padres & & 15 & 15 \\
\hline Embarazo ilegítimo & 5 & & 5 \\
\hline Muy pequeño el último hijo & 12 & 6 & 18 \\
\hline El marido niega la paternidad & 3 & 1 & 4 \\
\hline Temor al embarazo & 15 & 10 & 25 \\
\hline Por hijos defectuosos & 5 & 4 & 9 \\
\hline Prostitución & & 1 & 1 \\
\hline Desempleo del marido & 7 & 2 & 9 \\
\hline No sabe de quién es el hijo & & $1 \overline{2}$ & 12 \\
\hline Muchos hijos & 18 & 9 & 27 \\
\hline No se quiere casar el marido & & 6 & 6 \\
\hline El esposo tiene otra mujer & 14 & 7 & 21 \\
\hline No quería abortar, consultó por molestias del embarazo & 3 & 1 & 4 \\
\hline Puramente económica & 49 & 51 & 100 \\
\hline El marido es alcohólico & 3 & 1 & 4 \\
\hline El marido es agresivo & 4 & 3 & 7 \\
\hline El marido es alcohólico y agresivo & 7 & 6 & 13 \\
\hline Económica, esposo alcohólico y agresivo & 5 & 4 & 9 \\
\hline Económica, esposo alcohólico & 6 & 4 & 10 \\
\hline Económica, esposo agresivo & 3 & 5 & 8 \\
\hline
\end{tabular}

\section{CUADRO No 21}

CONDICIONES ECONOMICO-SOCIALES DEL GRUPO -ESTUDIADO-

\begin{tabular}{lcccccccccc}
\hline \multicolumn{1}{c}{ Abortos } & \multicolumn{1}{c}{ Hijos vivos } \\
\hline Casos & Emb. & Espont. & Provoc. & $N^{0}$ & $\begin{array}{c}\text { Edad } \\
\text { escolar }\end{array}$ & Se educan & $\begin{array}{c}\text { Hijos } \\
\text { muertos }\end{array}$ & $\begin{array}{c}\text { Costo } \\
\text { aborto }\end{array}$ & Arriendo & $\begin{array}{c}\text { Ingreso } \\
\text { cápita }\end{array}$ \\
\hline $\begin{array}{l}\text { Solteras } \\
161\end{array}$ & 3,2 & 8 & 187 & 1,8 & 123 & $57 \%$ & $22 \%$ & $\$ 70,00$ & $\$ 113,00$ & $\$ 124,00$ \\
\hline $\begin{array}{l}\text { Casadas } \\
180\end{array}$ & 6,2 & 38 & 224 & 4,1 & 322 & $75 \%$ & $13 \%$ & $\$ 60,00$ & $\$ 134,00$ & $\$ 102,00$ \\
\hline
\end{tabular}

El estado socio-económico en los grupos estudiados revela una condición de pobreza alarmante, mayor en los hogares de las casadas quienes tienen más hijos vivos, 4,1 en prome- dio, poco más del doble que las solteras, 1,8.

Procuran la educación de sus hijos en proporción discretamente superior 
las casadas, en tanto que las solteras no educan dos de cada cuatro.

El arrendamiento que pagan es de $\$ 113,00$ en las solteras y $\$ 134,00$ en las casadas. De todos modos el tipo de vivienda suele ser la pieza de inquilinato; el hacinamiento es la norma habitual.

Se halló que trabajaban para ayudar al sostenimiento de su hogar un $50 \%$ de las casadas y un $77,6 \%$ de las solteras.

Una mujer con $\$ 120,00$ mensuales debe atender las necesidades de seis personas; de sus cuatro hijos, tres están en edad escolar.

Otra casada con siete hijos vivos - cinco de ellos escolares que educa-, dispone de $\$ 400,00$ mensuales como ingreso total; es decir apenas $\$ 44,00$ para cada persona por mes.

Entre las solteras se informa un caso de $\$ 480,00$ de ingreso total para una familia de ocho hijos vivos, cinco en edad escolar de los que se educan dos.

Hay otra con $\$ 210,00$ para seis personas, entre ellos tres hijos en edad escolar que sólo educa uno.

La motivación por el aspecto económico es bien alta $-38 \%$ si bien en buen número de casos conlleva otros factores.

El número de maridos alcohólicos, el de los que golpean a sus mujeres, quienes niegan la paternidad, los que abandonan el hogar, los que mantienen una mala relación hogareña, más los que tienen otra mujer, sumados a los que presionan la realización del aborto, alcanzan un total de 166, o sea un $48 \%$, que es lo que podría llamarse la responsabilidad del marido en la incidencia del aborto criminal.

Hecho de grave implicación social es el de las mujeres que no son admitidas como trabajadoras por tener hijos o estar embarazadas. Las solteras que se ven abandonadas a su propia suerte en el trance de la gestación, las que temerosas de sus padres a quienes no pueden confiarse prefieren el camino del aborto con sus complicaciones biológicas y morales, más las que esperan inútilmente por una unión matrimonial que no llega, son todas víctimas de una falla en la legislación que requiere ciertamente una revisión.

Se anotan así mismo quienes ofrecen como motivo pretextos menores como el tener un hijo pequeño, o sentir temor por el embarazo y el parto. Otras por el miedo de dar a

\section{CUADRO N: 22}

\section{CONOCIMIENTO DE ANTICONCEPTIVOS}

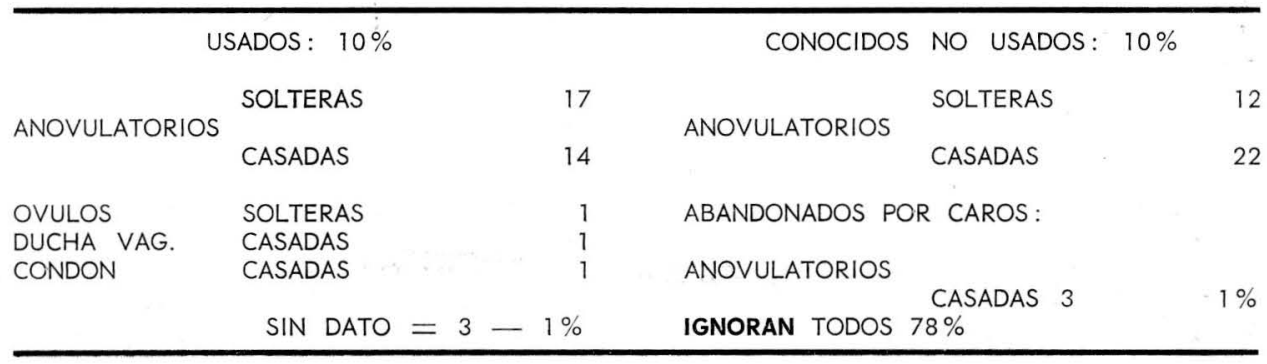




\section{CUADRO № 23}

\section{ANOVULATORIOS Y CONDICIONES ECONOMICO-SOCIAL}

\begin{tabular}{|c|c|c|c|c|c|c|c|c|c|c|c|}
\hline & Anovul. & Casos & Emb. & $\begin{array}{r}A b \\
\text { Espont. }\end{array}$ & $\begin{array}{l}\text { tos } \\
\text { Provoc. }\end{array}$ & $\mathbf{N}^{0}$ & $\begin{array}{l}\text { Hijos vivos } \\
\text { Edad escolar }\end{array}$ & Se educan & Hijos muertos & Arriendo & $\begin{array}{l}\text { Ingreso } \\
\text { cápita }\end{array}$ \\
\hline \multirow{2}{*}{ SOLTERAS } & NO USADOS & 12 & 3,4 & - & 100,0 & 1,6 & 30,0 & $66 \%$ & $26 \%$ & $\$ 115,00$ & $\$ 110,00$ \\
\hline & IGNORAN & 130 & 3,8 & 4,5 & 95,5 & 2,0 & 26,5 & $83 \%$ & $22 \%$ & $\$ 125,00$ & $\$ 125,00$ \\
\hline \multirow[t]{2}{*}{ CASADAS } & NO USADOS & 22 & 6,4 & 4,7 & 95,3 & 4,4 & 45,9 & $63 \%$ & $9 \%$ & $\$ 111,00$ & $\$ 108,00$ \\
\hline & USADOS & 14 & 6,0 & 4,8 & 95,2 & 3,3 & 43,7 & $100 \%$ & $9,5 \%$ & $\$ 152,00$ & $\$ 114,00$ \\
\hline
\end{tabular}


luz un hijo defectuoso, en veces porque ya tienen uno retardado.

Los casos de embarazo adulterino, 5 , y los de las 12 que ignoraban de quién estaban embarazadas - verdadera tragicomedia - también aportan incidencia.

Antes hemos anotado y ahora queremos recalcar, aquellos casos en que las maniobras abortivas fueron realizadas contra el deseo de la mujer que consultó por molestias de la gestación.

\section{Conocimiento de Anticonceptivos}

Sólo un $11 \%$ del total de mujeres encuestadas habría utilizado algún anticonceptivo, de ordinario anovulatorios, generalmente insinuados 0 aconsejados por las amigas.

Se halló que un 10\% más, habían oído hablar de "tabletas" pero sin atreverse a usarlas por distintas condiciones, la más frecuente, defectuosa información.

Tres mujeres casadas los habían abandonado porque su costo no se adaptaba a su situación económica.

$78 \%$ de las pacientes ignoraban todo procedimiento.

Se analizó la situación económica de tres grupos: las que habían utilizado los anovulatorios, las que no los habían usado, y el de quienes los ignoraban totalmente.

El número de embarazos de los grupos de solteras osciló de 3,4 a 3,9 sin variaciones significativas; entre las casadas el promedio es mucho mayor de 6;0 a 6,4.

En cuanto a los abortos provocados hay uniformidad de datos para todas las pacientes con un índice del $95 \%$, de modo que este es el sistema habitual de ellas para planificar su familia.

El número de hijos vivos de las mujeres casadas es prácticamente el doble del anotado para las solteras. Igualmente es mayor en las casadas el número de niños en edad escolar; muchos de ellos no reciben ninguna educación, en proporción algo mayor entre las solteras.

Una diferencia importante se anota en la proporción de hijos muertos cuyos índices promedios se duplican en las madres solteras.

La situación económica aparece reflejada en dos aspectos: el arrendamiento que pagan, $y$ el ingreso per cápita. Se refiere a sumas ridículas para ambos aspectos, con ligera diferencia en favor de las mujeres solteras; y no ofrece variación significativa en relación al grupo general en estudio.

\section{Soluciones}

Queremos insistir nuevamente en la necesidad de afrontar sin demora el problema del aborto provocado.

Lograr una nueva estructura social que modifique conceptos básicos inculcando saber y moral, parece el punto clave, cuya realización ciertamente ha de tomar años, tantos más cuanto más se demore su iniciación. La educación sexual, la protección para la mujer embarazada casada o soltera, la paternidad responsable, son elementos a considerar. Bien entendido que la unidad moral requiere un mínimo de unidad socio-económica.

En tanto que una realización así se desarrolla es necesario luchar contra las abortadoras, para lo cual, a nuestro entender, se requiere exculpar a las mujeres que declaren ante los 
jueces las mismas verdades que a nosotros han confiado.

Si las únicas que están en capacidad de mantener los cargos criminales a las abortadoras son sancionadas al igual que aquellas, es lógico suponer que no habrá acusadoras.

Como en nuestro informe anterior queremos incluir una estadística obtenida por las religiosas del Instituto cuya veracidad por tanto está fuera de dudas. Los datos son francamente alarmantes.

Las mujeres solteras que llegan al Instituto son el $66 \%$, o sea que sólo una de cada tres está unida por matrimonio.

El número de abortos provocados ha sido una sorpresa, pues sabíamos de su alta incidencia que en el año de 1965 se calculó en un 87\%, y ahora verificamos la cifra en un $82,9 \%$. Es decir que la excepción es el aborto espontáneo.
Hemos incluído el número global de niñas, que eso son las menores de 15 años, ya que al reducirlo a porcentaje parece perder significación: 3.204 en total estaban bajo esa edad. Su número es monstruoso si se tiene en cuenta que para 1965 era de 327.

Los niños abandonados fueron 221 en 1966 y 490 en 1965.

De incestos se contabilizan 65 casos. Es de advertir que en el sentir de las Religiosas que hacen la encuesta, por la corta permanencia hospitalaria de esas pacientes -apenas 3,3 días en promedio para 1966-, y menor de 3 en 1967, el número de datos en cuanto a incestos, y aborto provocados podría aumentarse significativamente si transcurriera un tiempo suficiente para lograr la confianza de las enfermas.

El número de confesiones y comuniones impartidas en el Instituto confirma el hecho de que estas mujeres se creen católicas y practicantes.

\section{CUADRO № 24}

DATOS OBTENIDOS POR LAS RELIGIOSAS I.M.I. EN 1966

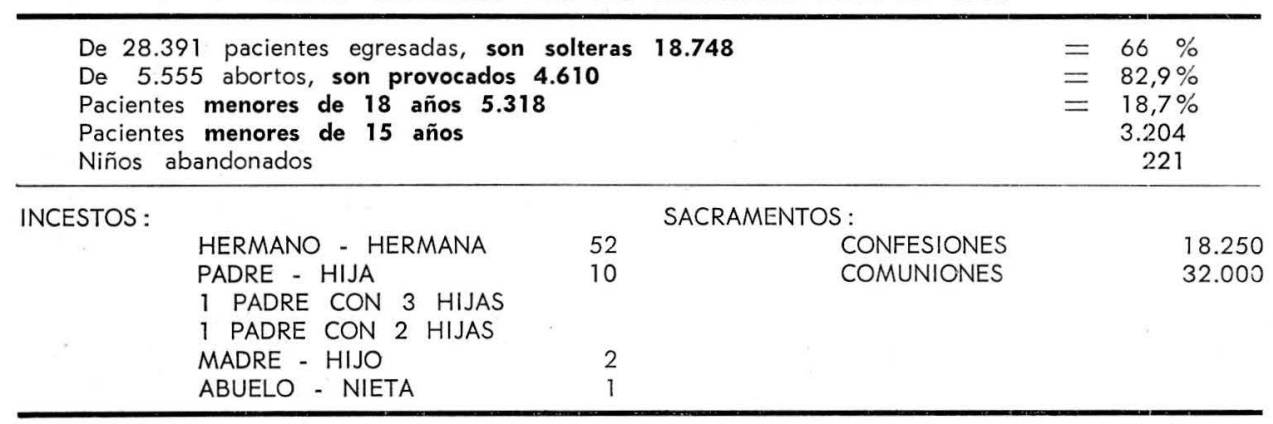

\section{RESUMEN}

Se informan 665 casos de aborto séptico ordinariamente relacionado con maniobras abortivas, que en 43 casos se verificaron en mujeres no embarazadas. La distribución por estados de infección muestra una alta incidencia de los casos con extensión a estructuras parauterinas, al peritoneo o con septicemias, (226 pacien- 
tes). La mortalidad hospitalaria es del $4,5 \%$ con porcentajes del 13,5 para la peritonitis y del 39,5 para la septicemia.

2) La bacteriología muestra un predominio del colibacilo y el estafilococo; Estreptococos, proteus, escherichia, neisseria, welchii y pseudomona, aparecen en menor número de casos. Se recalca la agresividad del estafilococo aureus, el estreptococo $y$ el welchii.

3) Se hace un esquema de manejo clínico orientado al diagnóstico precoz de las complicaciones. El manejo terapéutico se refiere fundamentalmente a la antibioterapia a base de Penicilina o Rifamicina en varias asociaciones. El manejo quirúrgico se discrimina por estados de infección.

4) La mortalidad se refiere según los estados de infección, los gérmenes causantes y las diversas complicaciones. Se demuestra el mal pronóstico vinculado a las lesiones hepáticas, renales y pulmonares.

5) Una investigación sobre maniobras abortivas muestra su alta frecuencia, mayor entre las mujeres casadas; se muestra el número de gentes implicadas como abortadoras, cuáles los métodos utilizados y el costo de las maniobras. En la motivación para el aborto se recalca la importancia del marido como factor determinante, de la situación económica y la incultura general que se manifiesta aún en el campo religioso pues todas se creen católicas y practicantes.

6) Se incluye una estadística obtenida por las religiosas del I. M. I. que muestra cómo un $66 \%$ de las mujeres ingresadas son solteras; que el 82,9 del total de abortos ingresados, son abortos provocados; se muestra cómo un número alarmante de muje- res menores de 15 años, 3.204 en total ingresaron en el año de 1966. Además se contabilizan 221 casos de niños abandonados y 65 de incestos. Finalmente se anota un número de confesiones y comuniones que verifica cómo se creen católicas y practicantes las pacientes ingresadas.

\section{BIBLIOGRAFIA}

1 AMAYA, L. H., y FLOREZ, A. J.: Tuberculosis y Embarazo. Rev. Colomb. Obst. Ginec. XVI: 357, Sept-Oct. 1965.

2 BARNO, ALEX: Criminal abortion deaths, illegitimate pregnancy deaths, and suicides in pregnancy, Am. J. Obstet. and Gynec. 98: 365, ss. Jun. 19 1967.

3 BAUER, H. A.: Staphylococci resistance to antibiotics: observations at two Hospitals and Independient Clinic, Northwest Med. 64: 247-51.

4 CAZZELA, D.: La rifamicina S V (rifocin) nella profilassi e nella terapia ostetrica e ginecologica. Quad. Clin. Ostet. Ginec. 19: 362. 1964.

5 DEANE, M. R.: Enterobacillary septicemia and bacterial shock in septic abortion. Am. J. Obstet. and Gynec. 79: 529, marzo 1960.

6 Encyclopédie Medico-chirurgical: Gynécologie. 11, 830 A 10. Ed. Séguier, Paris (6:)

7 FALK, C. H., BLINICK, G.: Management of post-abortal peritonitis. Am. J. Obstet. and Gynec. 54: 315, agosto 1947.

8 GIANNICE, C.: La rifamicina SV associata a mezzo di contrasto idrosolubile nella prevenzione del rischio da flogosi da isterosalpingografia (G. I. S.). Chemotherapia (Basel), 1963, 7, 167.

9 GIANNICE, C.: Considerazioni sull'impiego per via locale della rifamicina SV in campo ginecologico. Arch. Ist. S. Corona, 29: $234,1964$.

10 BASSAT, B. M.: Fatal Claudia septicemia developing after Hysterectomy and transfusion. Am. J. Obstet. and Gynec. 98: 8856, Julio 15, 1967.

11 GOODNO, A. J. CUSHNER, M., IRONIG, M. and MOLUMPHY, E. P.: Managemont of infected abortion. Am. J. Obstet. and Gynec. 85: 17, enero 19 1963. 
12 GORDON, A. H.: Animales libres de gérmenes: una ampliación del concepto de cultivo puro. Triángulo. 7: 108-55, 1966.

13 JAWEST, E. MELNICK, L. J. and ADELBERG, A. E.: Manual de Microbiología médica, 2a ed. M. M. México, 1966.

14 JOSEY, W. E., HOCH, W., MOON, E. C. and THOMPSON, J. D.: Análisis of 21 septic obstetrions deaths with special reference to the Schwartzman phenomenon, Obst. and Ginec, 28: 335, Sep. 1966.

15 JUNIS, J. A.: Toxicidad del Cloranfenicol, Conferencia en el Hospital de La Misericordia. Bogotá, 1967.

16 LOZANO-CARRILLO, A.: Peritonitis y Pelviperitonitis. Rev. Col. Obstet. Ginec. 17: 75-81, Enero-Febrero 1966.

17 PULLEN, L. R.: Pulmonary diseases. Edit. H. Kimpton. Londres. 1955, pp. 284.
18 PLANELLENES, J., JARITONOVA, A.: Efectos nocivos consecutivos al empleo de antibióticos en el tratamiento de las Enfermedades Infecciosas. Ed. Española. Moscú.

19 SANTAMARIA, P. L.: Aborto séptico y maniobras abortivas. Rev. Colomb. Obst. Ginec. XVII, 273--290, julio-agosto 1966.

20 SIMON, J. H.: Attenuated Infection, Lippincott Co. Philadelphia. 1960.

21 WEINSTEIN, L., LESNER, I. P., and CHEW, H. W.: Clinical and Bacteriologic studies of effect of massive doses of Penicillin $G$ on infections caused by gram negaitve bacilli. New England J. Med. 271: 525-33, Sep. $1 \%, 1964$.

22 Religiosas del I. M. I. Madre Ana María del Campo. Comunicación personal. 